\title{
Emerging drugs for sickle cell anemia.
}

\author{
Priya C Singh \\ Bayhealth Cancer Institute
}

Samir K. Ballas

Thomas Jefferson University

Follow this and additional works at: https://jdc.jefferson.edu/cardeza_foundation

Part of the Hematology Commons

Let us know how access to this document benefits you

\section{Recommended Citation}

Singh, Priya C and Ballas, Samir K., "Emerging drugs for sickle cell anemia." (2015). Cardeza

Foundation for Hematologic Research. Paper 39.

https://jdc.jefferson.edu/cardeza_foundation/39

This Article is brought to you for free and open access by the Jefferson Digital Commons. The Jefferson Digital Commons is a service of Thomas Jefferson University's Center for Teaching and Learning (CTL). The Commons is a showcase for Jefferson books and journals, peer-reviewed scholarly publications, unique historical collections from the University archives, and teaching tools. The Jefferson Digital Commons allows researchers and interested readers anywhere in the world to learn about and keep up to date with Jefferson scholarship. This article has been accepted for inclusion in Cardeza Foundation for Hematologic Research by an authorized administrator of the Jefferson Digital Commons. For more information, please contact: JeffersonDigitalCommons@jefferson.edu. 


\title{
Emerging Drugs for Sickle Cell Anemia
}

\begin{abstract}
Introduction: Sickle cell anemia (SCA) is caused by a single point mutation, which results in chronic vasculopathy and end organ damage. Over the past decades, hydroxyurea (HU) has been the standard treatment and therapies aimed at increasing fetal hemoglobin $(\mathrm{Hb}) \mathrm{F}$ were the focus of research. Our increased understanding of the complex pathophysiology of SCA has led to the development of novel targets involved in vaso-occlusion.

Areas covered: In this review, we describe the pathophysiology of sickle cell disease (SCD) and provide an in-depth analysis of the current and new pharmacologic therapies in the field.

Expert opinion: SCA is a heterogeneous disease that has caused tremendous global morbidity and early mortality. More effective, individualized and inexpensive therapies are needed. New therapies targeting multiple pathways in its complex pathophysiology are under investigation.
\end{abstract}

Keywords: Hydroxyurea, Sickle cell, Sickle cell anemia, Sickle cell disease, Sickle cell therapy, Sickle cell treatment 


\section{Background}

Sickle cell anemia is among the most common inherited hemolytic anemia, and affects an estimated 70,000-100,000 persons in the United States and likely millions worldwide. The true global incidence of SCD is unknown. The World Health Organization has estimated that each year 220,000 babies are born with SCD in Africa, and that SCD accounts for up to $16 \%$ of deaths of children aged $<5$ years in some African countries [1, 2]. The reported prevalence of the sickle cell trait in African Americans varies from $6.7 \%$ to $10.1 \%$ and in Africans the range is from 10 to $40 \%$ across equatorial Africa and decreases to between 1 and 2\% on the North African coast and less than $1 \%$ in South Africa [3-5]. The prevalence of the sickle cell trait varies widely worldwide and may be as high as 50\% in certain regions [5-7]. The prevalence of SCA is approximately 1 in 600 newborn African American infants and 150,000 to 300,000 newborn Africans [8-10].

Sickle cell anemia is a hereditary disorder of $\mathrm{Hb}$ where the sickle gene is inherited, homozygously, from both parents. The sickle mutation is the result of a single base change $(\mathrm{GAT} \rightarrow \mathrm{GTT})$ in the sixth codon of exon 1 of the $\beta$-globin gene responsible for the synthesis of the $\beta$-globin polypeptide of the Hb molecule $\left(\alpha_{2} \beta_{2}\right)$. This change I, in turn, results in replacement of a normal glutamic acid with valine at position 6 of the $\beta$-globin chain and the formation of sickle $\mathrm{Hb}$. Sickle erythrocytes are rigid with decreased deformability and reduced life span resulting in hemolysis, vasoocclusive disease, vasculopathy and subsequent inflammation and end organ damage [11, 12]. 
Clinical manifestations of SCD includes pain syndromes, anemia and its sequelae, organ failure including infection/inflammation and co-morbid conditions [13]. Despite having a common genetic basis and similar pathophysiology, individual patients with SCA have a highly variable clinical phenotype. Clinical care for affected individuals has been mostly supportive, including red blood cell transfusions (RBC), iron chelation, intravenous hydration, analgesics and antibiotics. The development of drugs to increase fetal $\mathrm{Hb}$ has been the major therapeutic strategy in the treatment of this disorder. Although new fetal $\mathrm{Hb}$-modulating agents are being studied, only $\mathrm{HU}$ has shown long-term benefit and remains the only United States Food and Drug Administration (FDA) approved therapy for SCA since 1998 [14]. The major aim of this review is to describe emerging pharmacologic therapies for SCA.

\section{Medical Need}

The ideal drug for SCD would have analgesic properties, be able to prevent vasoocclusive pain crises (VOCs) or abort with a rapid onset of action, would decrease the severity and frequency of VOCs, have limited hazardous side effect profile and be effective in all patients, and available globally. Currently $\mathrm{HU}$ is the only agent that fits certain of these criteria. It decreases the frequency of VOCs, acute chest syndrome (ACS), and thus improves quality of life and mortality in those with SCD. However HU is not effective in about $25 \%$ of those with SCD and may be teratogenic and possibly carcinogenic [15]. Management of patients with SCD in VOCs includes additional supportive measures with intravenous fluids, and analgesia and prophylaxis against thromboembolism when they are hospitalized. 


\section{Existing treatment}

Current approaches to management of SCD include supportive therapies such as folic acid, immunization and psychosocial support; symptomatic treatment which involves analgesics and blood transfusion; abortive therapy such as nitric oxide (NO); curative therapies such as bone marrow transplantation and gene therapy $[13,16]$. Preventative therapy is another current approach to the management of SCD which involves prophylactic antibiotics for infants and children, immunization, avoidance of known precipitating factors, cellular rehydration and $\mathrm{HU}$ for the induction of $\mathrm{Hb} \mathrm{F}$ [13, 16-21].

Hydroxyurea was identified as a potent $\mathrm{Hb} \mathrm{F}$ inducer and was subsequently found to be both a feasible and effective treatment option for SCA [12]. The mechanisms by which $\mathrm{HU}$ induces $\mathrm{Hb} \mathrm{F}$ production are not fully clear. It was felt to inhibit ribonucleotide reductase, an intracellular enzyme that converts ribonucleotides to deoxyribonucleotides, necessary for DNA synthesis and repair. More complex effects involve the production of NO, guanylyl cyclase and cGMP-dependent protein kinase pathway important in inducing expression of the $\gamma$-globin gene. Additionally HU improves erythrocyte deformability, lowering of circulating leukocytes and reticulocytes, and reduces hemolysis [2, 14, 22]. Since its first clinical application reported in 1984 by Platt and colleagues many trials were performed [18]. The Multicenter Study of Hydroxyurea in SCA (MSH), a placebo controlled randomized phase III trial of 299 adults with severe SCA, which terminated early due to significant reductions in frequency of VOC, ACS, need for blood transfusion and delayed onset of first VOC [23, 24]. This study led to the FDA approval of HU for therapy in severely affected adults with SCA in 1998. Last year 
witnessed the culmination of a decade-long Phase III clinical trial (BABY HUG)

involving infants with SCA randomized either to HU (fixed dose $20 \mathrm{mg} / \mathrm{kg} /$ day) or

placebo. BABY HUG showed that HU did not clearly prevent organ damage in a 2-year

treatment period, but significantly decreased pain, ACS, hospitalizations, and transfusions in children [25-30].

Additionally, some of the current approaches to the management of SCD could be pharmacologic or non-pharmacologic especially when it comes to pain management. Examples of non-pharmacologic treatments include meditation, therapeutic massage, transcutaneous electrical nerve stimulation, heat and cold packs, distraction, relaxation, music, guided imagery, self-hypnosis, acupuncture and biofeedback [13, 16]. Current examples of pharmacologic therapies include the use of NSAIDs, opioids, adjuvants, steroids, etc [13].

\section{Market review}

Sickle cell disease is a global disease affecting millions of people worldwide and hundreds of thousands in the United States. It not only affects those of African descent, but also persons of Middle Eastern, Indian, Latin American, and Mediterranean descent. It has received very little attention and even less research funding. National Institute of Health (NIH) grants for sickle cell research was much less than that for less common inherited diseases. In 1972, the National Sickle Cell Anemia Control Act (NSCACA) was signed, which paved the way for more research funding and established screening and 
education programs. The NIH dedicated $\$ 10$ million to be spent on SCD research at that time [13].

The economic burden to patients with SCD is significant [31-35]. Many patients are living in poverty with their illness due to chronic pain, and physical disability limiting their ability to work and contribute to society [13]. The economic burden on society was estimated at $\$ 1.1$ billion in 2009 [31]. This number is projected to increase as patients with SCD are living longer as we continue to improve supportive care. A solution to this problem is not simple requiring multidisciplinary action with increased funding, legislation, research and supportive services. Simple therapy with HU is still not available to the millions in Africa today. As we continue to push for new therapies for SCD, HU has tremendous potential on the global market.

\section{Current research goals}

Hydroxyurea has many qualities of the ideal agent for SCD and it is felt to be successful primarily through its actions of increasing fetal $\mathrm{Hb}$. Increased fetal $\mathrm{Hb}$ has been associated with a less severe phenotype, which has spurred interest in the identification of pharmacologic agents capable of inducing $\mathrm{Hb} \mathrm{F}$ expression. The sickle cell population has varied phenotype, which makes targeted therapy more attractive to achieve better outcomes. There are fewer patients with SCD in the United States where most clinical trials are available. There are also challenges with clinical trial enrollment since patients are impoverished and in pain limiting their abilities to effectively participate in a clinical trial. Research focus is changing to incorporate a multi-agent approach to treating patients and in re-engineering clinical trial design. 


\section{Scientific rationale}

Since sickled cells were first described in 1910 and mutation causing abnormal $\mathrm{Hb}$ S was identified in 1949, the complex mechanism underlying its pathophysiology continues to evolve [36]. A cascade of events driven by endothelial damage and inflammation leads to vasculopathy. The inciting event is injury to the RBC membrane. Hemoglobin S polymerization impairs deformability of the RBC and causes oxidative injury and destruction of the RBC. Red blood cell injury exposes phosphatidyl serine and releases $\mathrm{Hb}$ and other intracellular contents. This in turn depletes NO, increases endothelial adherence, releases pro-inflammatory cytokines and activates the coagulation cascade causing ischemia, reperfusion injury and vascular damage $[11,15,36]$.

Damaged sickle cells are prone to adhere to the endothelium by adhesion molecules. The RBC membrane receptors VLA-4/ $\alpha_{4} \beta_{1}$ bind to endothelial receptors directly to vascular cell adhesion molecule 1 (VCAM-1) and interacts with subendothelial matrix proteins (BCAM/LU, $\alpha 4 \beta 1$ with the laminin and VWF) [37, 38]. Red blood cell interactions with the vascular endothelium also lead to the production of oxygen radicals by activating transcription factor NF- $\mathrm{B}$. Nuclear factor kappa-light-chain-enhancer of activated B cells up-regulates the production of endothelial adhesion molecules such as E-selectin, VCAM-1, and intracellular adhesion molecule-1 (ICAM-1). P-selectin and E-selectin on endothelial cells have been suggested to participate in VOC [39, 40]. In preclinical studies an anti-P-selectin molecule showed increased microvascular flow and reduced adhesion of leukocytes to the endothelium [39]. Intracellular adhesion molecule-4 
(ICAM-4), another RBC membrane protein, participates in adhesion can be activated by epinephrine to adhere to endothelial membrane and exacerbate vasoocclusive disease and also increased leukocyte adhesion to endothelium [40]. When treated with Propranolol (a $\beta$-adrenergic receptor antagonist) VOCs were diminished [41, 42]. In addition to adherence to endothelial cells, RBCs in SCA also adhered strongly to leukocytes in venoocclusive crises via interactions with P-selectin and E-selectin. This interaction is propagated by TNF-alpha. Selectins function in adhesion to the vessel wall by recruiting rolling particles and cells and also contribute to cell activation.

Patients with SCD have chronic elevation of proinflammatory cytokines at baseline, including C-reactive protein, TNF, IL-1, IL-8. Damaged RBCs, activated endothelial cells, leukocytes and platelets contribute to a proinflammatory environment. Sickled RBCs stimulate endothelial cells to release TNF-alpha and IL1-beta. There is increased production of placental growth factor, which activates monocytes to release reactive oxygen species which enhances inflammation. Additionally invariant natural killer $\mathrm{T}$ (iNKT) cells are activated in patients with SCD suggesting that iNKT cells may play a critical role in mediating inflammation. Intravascular hemolysis results in release of cell free $\mathrm{Hb}$ in plasma, and hemin release that contribute to the inflammation [38, 43].

Nitric oxide is produced by the endothelium from arginine and causes vasodilation by binding to endothelin-1, a vasoconstrictor. Intravascular hemolysis releases $\mathrm{Hb}$, which scavenges NO in the plasma and subendothelial spaces. Depletion of NO leads to vasoconstriction and formation of reactive oxygen species. Nitric oxide also 
downreguates adhesion molecules, (VCAM-1), ICAM-1 and E-selectin. Erythrocyte arginase released during hemolysis decreases arginine levels and decreases NO production. The byproducts of these reactions: urea, proline, polyamines and free radicals cause vascular remodeling and vasculopathy. Patients with SCD have elevated asymmetric dimethylarginine, which inhibits arginine transport, promotes endothelial dysfunction $[15,44,45]$.

These inflammatory processes activate the coagulation cascade. Phosphatidylserine expression on RBC surface and microparticles activates tissue factor and in turn, the extrinsic coagulation cascade. Tissue factor also promotes inflammation and endothelial damage. In preclinical studies in transgenic sickle mice, lowering tissue factor levels resulted in lower plasma levels of IL-6 and soluble VCAM-1 [46].

Sickle cell disease is a chronic inflammatory state and reactive oxygen species (ROS) are increased at baseline compared with normal controls. Hemolysis releases $\mathrm{Hb}$, and iron products, which increase ROS that generate superoxide $\left(\mathrm{O}_{2}^{-}\right)$and peroxynitrate (ONOO-), which promotes an inflammatory response and causes cell death. Patients with SCD have impaired buffer system with decreased glutathione, and other antioxidants [47-49].

\section{Competitive environment}

\subsection{Fetal Hemoglobin Inducing agents}

Two novel Hb F-inducing agents, pomalidomide and sodium dimethylbutyrate, are 
promising targets to increase fetal $\mathrm{Hb}$. Pomalidomide is an orally active thalidomide analogue. Preclinical studies showed that it induced $\mathrm{Hb}$ F production in a SCD model with similar efficacy as HU. Surprisingly, pomalidomide improved erythropoiesis in comparison to myelosuppresion seen with HU. However, when given in combination with $\mathrm{HU}$, this effect was lost and fetal $\mathrm{Hb}$ levels were suppressed [50]. A phase I study of pomalidomide in SCD was completed. Twelve patients enrolled and data has not been published (clinicaltrials.gov, trial identification NCT01522547).

HQK-1001, sodium dimethylbutyrate is an orally-active short chain fatty acid derivative, under development by HemaQuest ${ }^{\text {TM }}$ for the treatment of SCA and beta-thalassemia. It was found to increase fetal $\mathrm{Hb}$ and $\mathrm{Hb}$ levels in Phase I trials [51]. A randomized, placebo-controlled Phase II trial enrolled 77 patients with SCD in Canada, Egypt, Jamaica, Lebanon and the US and has been terminated. The primary objective was to evaluate for increase in fetal $\mathrm{Hb}$ levels. Interim analysis was expected in late 2013 and this data has not been yet been published. A phase III trial is expected in 2015 [51].

Additionally L-arginine, a substrate for NO, was evaluated in combination with $\mathrm{HU}$ in a small randomized trial of 21 adult patients with SCD. There was a greater response in fetal $\mathrm{Hb}$ levels and reticulocyte count in the group receiving combination therapy versus HU alone. This study suggests that fetal Hb synthesis depends on NO effect on erythroid progenitors [52].

Decitabine is an intravenous cytosine analog 5-aza-2'-deoxycytidine which 
hypomethylates DNA by inhibiting DNA methyltransferase. It is approved for treatment of myelodysplastic syndrome. It increases fetal $\mathrm{Hb}$ by reactivating the silenced $\gamma$-globin through hyomethylation at it's promoter site. In a small study of 8 patients refractory or intolerant to $\mathrm{HU}$, it increased $\mathrm{Hb} \mathrm{F}$ and $\mathrm{Hb}$ levels when administered subcutaneously [53]. Ongoing trials will further clarify its efficacy and tolerability. A phase II study with planned enrollment of 40 patients with high risk SCD is recruiting (NCT01375608). A phase 1 combination study of oral decitabine with tetrahydrouridine, a competitive inhibitor of cytidine deaminase, is also recruiting and its aim is to evaluate oral bioavailability of decitabine in combination therapy [54] (NCT 01685515).

Vorinostat, also known as suberanilohydroxamic acid (SAHA) is inhibitor of histone deacetylases (HDAC). Vorinostat is marketed under the name Zolinza TM for the treatment of cutaneous T cell lymphoma (CTCL). In preclinical studies, HDAC inhibitor trichostatin A (TSA) inhibited pulmonary vascular endothelial VCAM-1 and tissue factor expression, prevented vascular stasis in sickle mice, served as an iron chelator, and increased Hb F. Vorinostat, a TSA analogue exhibits the same effects [55]. Vorinostat is currently being evaluated in a Phase II clinical trial with target enrollment of 15 patients with SCD (NCT01000155).

\subsection{Targeting adhesion}

Rivipansel sodium, GMI-1070, is a small molecule pan-selectin inhibitor that binds to E,P and L selectin that was developed by GlycoMimetics to target inflammation in sickle VOCs. It improves blood flow by inhibiting E-selectin and neutrophil activation. A randomized, double-blind, adaptive Phase II trial of rivipansel in pediatric SCD patients 
with VOC of age $12-18 \mathrm{yr}$ is complete. There was $>50 \%$ reduction in time to transition to oral pain medications, as well as a reduction in time to hospital discharge, in each case compared to standard treatment for pain was observed. Statistical significance was achieved for time to transition to oral pain medication, however results for time to discharge and time to resolution of VOC, the primary endpoint, were not statistically significant. Safety results for the pediatric patients were consistent with prior findings in treatment of adult patients [56].

A randomized, double-blind, placebo-controlled Phase II trial in 76 subjects hospitalized for sickle cell VOC assessing GMI-1070 is complete. Data showed that the patients treated with rivipansel sodium experienced reduction in duration of VOC, length of hospital stay and reduction in the use of opioids for pain relief. Both adult and pediatric patients demonstrated improvement and adverse event rates were comparable between rivipansel sodium and placebo (NCT01119833). Results of these studies have not yet been published in a peer-reviewed journal [57].

Intravenous immunoglobulin (IVIG) also inhibits leukocyte adhesion and activation by binding to Fc $\gamma$ RIII expressed on neutrophils [58]. A Phase I/II trial is currently recruiting to evaluate Gamunex (Intravenous Gammaglobulin) versus normal saline in sickle cell acute pain (NCT 01757418).

Endothelial P selectin is involved in microvascular blood flow. Heparin, in addition to its anticoagulant effects, decreases adhesion of sickled erythrocytes by inhibiting P-selectin. Two clinical trials are evaluating the effect of prophylactic dose low-molecular-weight heparin (LMWH) to ameliorate the vaso-occlusive process and unfractionated heparin in 
ACS (NCT 01419977, NCT02098993).

In a randomized clinical trial of 253 patients, Tinzaparin, a low-molecular-weight heparin, showed reduced duration of VOC and no severe bleeding complications [59]. These results need to be validated in a multicenter study. A recent phase II trial of an oral P-selectin inhibitor (pentosan polysulfate sodium) similar to heparin but with greater Pselectin blocking ability than heparin showed improved microvascular flow in SCD patients in a phase 1 study [60]. The efficacy of SelG1, a humanized anti-P-selectin monoclonal antibody, in preventing VOC will be evaluated in an upcoming phase 2 trial in combination with HU (NCT01895361).

Studies suggest stress related adrenergic stimuli like epinephrine may contribute to vasoocclusion. De Castro and colleagues conducted preclinical and phase I studies to evaluate the role of propranolol, a beta adrenergic blocker, in SCD.

Propranolol significantly reduced $\mathrm{RBC}$ adhesion in a dose-dependent manner. Adverse events were not severe, did not vary with the dose administered and no elevation in heart rate was noted. These results imply that $\beta$-blockers have a potential role in inhibiting RBC adhesion [61]. A phase 2 study of propranolol in SCD has been completed and no data has been reported at the time that this manuscript was written (NCT 01077921).

The importance of activated platelets on the vasculopathy of SCD have led to clinical trials with antiplatelet therapy [62]. Eptifibatide, a synthetic GPIIb/IIIa peptide 
antagonist which inhibits platelet aggregation, was initially developed to treat acute arterial thrombosis. It was launched in the US in 1998 as Integrillin to treat angina, acute coronary syndromes and for use in percutaneous coronary angioplasty and it is approved in Europe. It has decreased platelet activation and increased vasodilation in the sickle cell population in clinical trials [63]. A placebo controlled phase 2 trial was completed. Thirteen patients with SCD were randomized to receive either eptifibatide or placebo. There were no major bleeding episodes in either arms and one minor bleeding episode in the eptifibatide arm. There were no differences in the median times to discharge, median times to crisis resolution or the median total opioid use. In this small study, eptifibatide appeared to be safe, but did not improve the times to crisis resolution or hospital discharge. Adequately powered studies are required to evaluate the safety and efficacy of eptifibatide in SCD [64].

Investigational therapies targeting multiple pathways are being studied. Rivaroxaban, a new orally active direct Factor-Xa inhibitor and serine protease inhibitor was FDA approved in the US as an anticoagulant for prophylaxis and treatment in acute coronary syndromes, cerebral ischemia, pulmonary embolism and venous thrombosis. It is currently being evaluated in a Phase II clinical trial in SCD to reduce inflammation, coagulation, endothelial cell activation, and improve microvascular blood flow in patients during the non-VOC, steady state (NCT02072668).

\subsection{Targeting inflammation}

In SCA patients there is increase in the number of activated invariant natural killer $\mathrm{T}$ 
(iNKT) cells. Regadenoson is an $A_{2 A}$ receptor $\left(A_{2 A} R\right)$ agonist reduces iNKT activation and thus decreases inflammation. A phase 1 study in 27 adults with SCD showed a $48 \%$ decrease in activation of iNKT cells compared to baseline after regadenoson was administered with no toxicities identified [65]. NKTT-120 is a humanized monoclonal antibody designed to target invariant Natural Killer T cells. Preclinical studies showed depletion of iNKT cells and no effect on other natural killer cells. The T cell antibody response was not impaired in reponse to a KLH challenge [66]. A phase I trial planned to enroll 21 patients with SCD is currently recruiting (NCT 01783691).

Carbon monoxide inhibits inflammation and hypoxia-induced vasoocclusion in transgenic mice [67]. MP4-CO is a human $\mathrm{Hb}$ conjugated to carbon monoxide via an MP4 molecule. It decreased mortality in sickle cell mice from hypoxia reperfusion injury and has anti-inflammatory properties [68]. A phase I study that enrolled 32 patients with SCD is complete. Data is not yet available (NCT01356485). A phase II study in patients with SCD has been withdrawn prior to enrollment.

The vascular injury seen in SCD has been described to share similarities with that of atherosclerosis. Statins decrease inflammation and improve endothelial function in cardiovascular disease and is under study in SCD. A pilot study of 26 patients treated with simvastatin showed a dose related decrease in inflammatory biomarkers (C-reactive protein and IL-6 levels) and increased NO metabolite levels [69]. A phase II trial of atorvastatin is enrolling by invitation (NCT01732718). 
Omega-3 fatty acids, EPA (eicosapentaenoic acid) and DHA (docosahexaenoic acid), are noted for their antiadhesive, anti-inflammatory, and vasodilatory effects. These are decreased in patients with SCD. A single institution study in Sudan was designed to evaluate its therapeutic effects in patients with SCD in a randomized, placebo-controlled, trial. One hundred and forty patients received omega-3 capsules for 1 year and omega-3 treatment reduced the rate of VOC events, red blood cell transfusions, and white blood cell count. The therapy was well tolerated and warrants further study [70].

Sickle cell disease patients have elevated levels of 5-lipoxygenase, a potent inflammatory leukotriene. Zileuton, a specific inhibitor of 5-lipoxygenase, is FDA approved for asthma. Beneficial effects in the SCD animal model have led to a phase 1 trial in SCD (NCT01136941).

$\mathrm{N}$-acetylcysteine (NAC), is the rate limiting substrate for glutathione generation, an important antioxidant with pleiotropic effects on inflammation [71]. NAC inhibits dense cell formation and restores glutathione levels toward normal. In pilot studies the administration of $\mathrm{N}$-Acetylcysteine resulted in a reduction of oxidative stress. A phase 2 double-blind, randomized clinical trial was completed to determine the efficacy of NAC in decreasing dense cell and irreversible sickle cell formation and VOC episodes in SCD. NAC inhibited dense cell formation, restored glutathione levels toward normal, and decreased VOC episodes [72]. A phase III trial is underway (NCT01849016). 
Prasugrel (Effient TM) is a member of the thienopyridine class of ADP receptor antagonist, like clopidogrel (Plavix ${ }^{\mathrm{TM}}$ ), which inhibits ADP induced platelet activation and aggregation by irreversibly binding to $\mathrm{P} 2 \mathrm{Y}_{12}$ receptors. It is FDA approved for use in acute coronary syndromes. In randomized trials in SCD, platelet activation was prevented and preliminary results suggest a decrease in pain rate [73, 74]. A phase 2 randomized, double-blind, placebo-controlled study examined safety of prasugrel measured by hemorrhagic events. Patients were randomized to prasugrel $5 \mathrm{mg}$ daily or placebo for 30 days. There were no hemorrhagic events requiring medical intervention in either study arm. Platelet surface P-selectin and plasma soluble P-selectin, both biomarkers of platelet activation, were significantly reduced in SCD patients receiving prasugrel compared with placebo. This study showed a decrease in platelet activation biomarkers and a trend toward decreased pain [75]. A phase II trial to determine dosing was completed in children and results are pending (NCT01476696). A phase 3 study in children is currently recruiting (NCT01794000).

Dysregulation of NO metabolism is a common denominator in the pathogenesis of vasculopathy. Inhaled NO in SCD has resulted in variable clinical responses. A recent phase 2 trial for adult SCD patients treated with NO for painful VOCs showed no benefit [76]. A phase II trial to evaluate NO to treat acute VOCs was completed. Results showed a longer time to resolution of VOCs with NO, however statistical analysis is not yet available (NCT00094887). Two trials in adults with SCA were completed and results have not been reported (NCT0009581, NCT00352430). Another study evaluating NO therapy for VOCs and ACS in children with SCD is recruiting (NCT01089439, 
NCT00142051).

Arginine is depleted in hemolysis due to the release of arginase and leads to decreased NO formation. In SCD patients with pulmonary hypertension, arginine supplementation increases plasma NO and rapidly decreases pulmonary artery pressure by $15 \%$ [77]. A recent randomized, double-blind, placebo-controlled study of high-dose arginine supplementation in hospitalized SCD patients with VOC was completed and found a > $56 \%$ reduction in narcotic use in patients receiving arginine compared with controls [78]. A phase II randomized trial in 38 children showed a significant reduction in opioid use and lower pain scores at discharge in those treated with arginine in comparison to the placebo arm. There was no significant difference in hospital length of stay and no toxicity was noted [79]. A study was just completed in children with SCD to evaluate the effectiveness of arginine at increasing NO levels, improving RBC function, and reducing hospitalizations and pain medication use. This was done by measuring gardos channel activity, mean corpuscular $\mathrm{Hb}$ concentration (MCHC) and $\mathrm{NO}$ levels. There was only statistically significant difference in low dose arginine with decreased MCHC versus placebo. Data is available but has not been published (NCT00513617). Other studies have been completed and awaiting analysis and 2 are currently recruiting (NCT01142219, NCT00056433, NCT00029731, NCT00004412).

\subsection{Targeting oxidative injury}

The primary buffer for reactive oxygen species is reduced glutathione. Glutamine is metabolized to glutamate, the glutathione precursor, and preserves intracellular 
nicotinamide adenine dinucleotide (NAD), which is necessary for glutathione recycling. Oral supplementation of glutamine in SCD increases the NAD redox potential and may improve sickle erythrocyte adhesiveness $[80,81]$. Oral glutamine is also used as a dietary supplement and it decreases the resting energy expenditure in children with SCD. A multicenter phase III trial of glutamine supplementation in 230 children to prevent VOC is completed and results are not available (NCT01179217). Two phase II trials are also complete and results have not been posted (NCT00125788, NCT00131508).

Alpha-lipoic acid augments cellular stress response by increasing the transcription of antioxidant genes, decreasing $\mathrm{NF}-\kappa \mathrm{B}$, and increasing glutathione synthesis. Acetyl-1carnitine is an essential nutrient that facilitates the entry of long-chain fatty acids into the mitochondria and decreases lipid peroxidation in tissue. Alpha-lipoic acid and acetyl-Lcarnitine have a synergistic antioxidant effect [82]. A recent Phase II trial combining antioxidants enrolled 42 patients to determine whether alpha-lipoic acid and acetyl-Lcarnitine will lower systemic inflammation in patients with SCD. This study is complete, however data is not available for review (NCT01054768).

Aes-103, 5-hydroxymethyl-2-furfural (5HMF), is a naturally occurring oral aldehyde that interacts with $\mathrm{Hb} \mathrm{S}$ in red blood cells increasing oxygen affinity and decreasing $\mathrm{Hb} \mathrm{S}$ polymerization. A preclinical study showed that 5-HMF decreased RBC dehydration in a deoxygenated state and inhibited activation of the Gardos channel and phosphatidylserine. We are awaiting results of two completed phase I trials and a phase II trial is currently recruiting [83-85] (NCT01597401, NCT01871142, NCT01987908). 


\section{Potential development issues}

The ideal drug to decrease the global disease burden would be an oral agent with no special handling and storage requirements. Many new drugs currently in clinical trial would mainly provide benefit for patients in the developed world. Additionally certain drugs like the hypomethylating agents may only be ideal in certain patient populations, more specifically in adults. Studies in the pediatric population are lacking and will warrant further study. It has been studied in children with acute myelogenous leukemia, however further long term data to evaluate long term side effects are needed. Its potential teratogenic and carcinogenic potential may limit applicability in women of childbearing age and in children. When looking at combining therapies, potential for hazardous side effects can be preventative. For example, bleeding risk is increased with antiplatelet therapy such as prasugrel, in combination with anticoagulation, such as heparin $[13,60$, 75].

\section{Conclusion}

Hydroxyurea has proven to be effective in SCD and has decreased morbidity and mortality in randomized phase III trials in adults and children. It is available both in the US and the rest of the world. Access in Africa still remains a challenge. Our improved understanding of the pathophysiology and its protean pathways led to many new drug targets. We reviewed 27 new drugs in development for the treatment of patients with SCD. Table 1 includes all the drugs discussed in this paper as well as others. 
The agents that primarily increase fetal $\mathrm{Hb}$ include pomalidomide, sodium dimethylbutyrate, decitabine and vorinostat. Pomalidomide, a thalidomide analog, is in a phase I trial and the hypomethylating agent, decitabine, and the HDAC inhibitor, vorinostat, are in phase II trials. Sodium dimehtylbutyrate, a short chain fatty acid, has completed phase II studies and a phase III trial is expected.

The drugs targeting adhesion primarily inhibit selectins and include rivipansel sodium, heparin, tinzaparin, pentosan polysulfate and SelG1. These are all in phase I and II trials. IVIG, propranolol, eptifibatide, and rivaroxaban also prevent adhesion to the vascular endothelium and are in phase II trials in the sickle cell population. We have long term experience and data with use of heparin, IVIG, tinzaparin, propranolol, eptifibatide and rivaroxaban for other hematologic illnesses and in the field of cardiology where they were studies in phase III trials and approved for many other indications.

Targets of the inflammatory process include regadenoson, carbon monoxide, simvastatin, atorvastatin, omega-3 fatty acids, zileton, $\mathrm{N}$-acetylcysteine, prasugrel, $\mathrm{NO}$ and arginine. Prasugrel and $\mathrm{N}$-acetylcysteine have reached phase III trials. Nitric oxide and arginine also function indirectly as fetal $\mathrm{Hb}$ induction agents. Arginine, a natural amino acid, is being evaluated in adults and children and has reached phase III studies.

Drugs under study to prevent oxidative injury include glutamine, alpha-lipoic acid, acetyl-L-carnitine and Aes-103. Glutamine, a dietary supplement, had reached phase III studies in children. Alpha-lipoic acid and acetyl-L-carnitine are studied as combination 
therapy in phase II studies.

\section{Expert Opinion}

There has been tremendous advance in our knowledge of the pathophysiology of sickle cell vascular injury over the past decade resulting in new therapeutic targets. The field is witnessing promising translational studies hoping to replace or use with $\mathrm{HU}$ as the primary pharmacologic therapy for patients with SCD. We reviewed therapies targeting increases in fetal $\mathrm{Hb}$ and the complex pathways in adhesion and inflammation.

Hydroxyurea is an oral agent that has decreased morbidity and mortality in adults and children with SCA. It decreases recurrent VOCs, ACS, blood transfusion requirements, and improves quality of life mainly through increasing fetal $\mathrm{Hb}$ production. It is inexpensive and potentially available worldwide. It is cytotoxic, which may cause myelosuppresion and it is contraindicated in pregnancy due to potential teratogenicity. It's carcinogenic effects are unknown and long term studies have failed to document this.

Decitabine is an attractive agent as it induced fetal $\mathrm{Hb}$ with similar disadvantageous risk profile like $\mathrm{HU}$ with potential myelosuppression, teratogenicity and carcinogenicity. It is already approved therapy for myelodysplastic syndrome, and acute myeloid leukemia; conditions more prevalent in the elderly. It is being evaluated in oral form and in combination therapy currently and further testing is warranted in the pediatric population. 
The oral HDAC inhibitor, vorinostat, is appealing for its potential multiple effects. In preclinical studies, its analogue TSA, not only induced $\mathrm{Hb}$ F, but reduced endothelial activation, prevented vascular stasis and exhibited iron chelation properties. Both of these agents are in phase II trials.

Glutamine, prasugrel, and $\mathrm{N}$-acetylcysteine have reached phase III trials. These work differently, targeting oxidative injury and inflammation and do not share the same side effect profile. A combination of any of these agents together or in combination with a fetal $\mathrm{Hb}$ inducing agent such as $\mathrm{HU}$ or vorinostat is a potential strategy to combat this disease.

Studies involving NO so far have been disappointing in the sickle cell population. It is surprising that arginine therapy was more promising than $\mathrm{NO}$ since its role is to increase NO. Nevertheless this natural amino acid is an ideal agent for a combination regimen. Similarly, omega-3-fatty acids has multiple effects, is effective in other illnesses, has a good side effect profile making it an ideal agent to combine with other therapies.

In the sickle cell population, there are challenges with clinical trial enrollment since it is a relatively rare and clinically heterogeneous disease. A paradigm shift in clinical trial design would improve outcome. Due to the complex pathophysiology of the disease, clinical trials targeting a multi-agent approach may be more successful as in oncology where combination chemotherapy regimens have been more efficacious. Trial design in SCD over the past 3 decades has historically incorporated all patients with SCA. Vichinsky proposed reassessing endpoints to see a benefit in a targeted phenotype and 
including quality of life measures. A modification of this concept is to target the different phenotypes upfront as in recent successful lung cancer drug trials, which incorporated biomarkers in patient selection.

In summary, our greater understanding of the pathophysiology of SCD has led to many new targets for drug therapy and with a paradigm shift in clinical trial design, we are in an exciting position to improve care for the millions who suffer with SCD.

\section{Bibliography}

Papers of special note have been highlighted as either of interest $(\bullet)$ or of considerable interest $(\bullet \bullet)$ to readers.

1. Odame I. Developing a global agenda for sickle cell disease: report of an international symposium and workshop in Cotonou, Republic of Benin. Am J Prev Med 2010 Apr;38(4 Suppl):S571-5.

\section{- An article discussing the global impact of sickle cell disease.}

2. McGann PT, Ware RE. Hydroxyurea for sickle cell anemia: what have we learned and what questions still remain? Curr Opin Hematol 2011 May;18(3):15865.

\section{- An article discussing the global impact of sickle cell disease.}

3. Castro O, Rana SR, Bang KM, Scott RB. Age and prevalence of sickle-cell trait in a large ambulatory population. Genet Epidemiol 1987;4(4):307-11.

4. Steinberg M H, Forget BG, Higgs D R, Weatherall DJ. Disorders of hemoglobin 2nd ed. Cambridge: Cambridge University, 2009.

5. Goldsmith JC, Bonham VL, Joiner CH, Kato GJ, Noonan AS, Steinberg MH.

Framing the research agenda for sickle cell trait: building on the current understanding of clinical events and their potential implications. Am J Hematol 2012 Mar;87(3):340-6.

6. Serjeant GR, Serjeant BE. Sickle Cell Disease. 3d ed. Oxford: Oxford University Press, 2001. 
7. Bunn HF, Forget BG. Hemoglobin: Molecular, Genetic and Clinical Aspects. Philadelphia: WB Saunders, 1986.

8. Ballas SK, Park D, Wapner RJ. Neonatal screening for sickle cell disease in a metropolitan university hospital: efficacy and problems. J Med Screen 1994 Oct;1(4):229-32.

9. Shafer FE, Lorey F, Cunningham GC, Klumpp C, Vichinsky E, Lubin B. Newborn screening for sickle cell disease: 4 years of experience from California's newborn screening program. J Pediatr Hematol Oncol 1996 Feb;18(1):36-41.

10. Diallo DA. Sickle cell disease in Africa: current situation and strategies for improving the quality and duration of survival. Bull Acad Natl Med 2008 Oct;192(7):1361-72; discussion 72-3.

11. Vichinsky E. Emerging 'A' therapies in hemoglobinopathies: agonists, antagonists, antioxidants, and arginine. Hematology Am Soc Hematol Educ Program 2012;2012:271-5.

- An excellent review of current investigational treatment and pathophysiology of Sickle Cell Disease.

12. Ware RE. How I use hydroxyurea to treat young patients with sickle cell anemia. Blood 2010 Jul 1;115(26):5300-11.

- A practical approach to treating sickle cell disease currently.

13. Ballas SK. Sickle Cell Pain, 2nd Edition. Washington DC: International Association for the Study of Pain, 2014.

14. Rees DC. The rationale for using hydroxycarbamide in the treatment of sickle cell disease. Haematologica 2011 Apr;96(4):488-91.

15. Kotiah SD, Ballas SK. Investigational drugs in sickle cell anemia. Expert Opin Investig Drugs 2009 Dec;18(12):1817-28.

16. Ballas SK. Sickle cell anaemia: progress in pathogenesis and treatment. Drugs 2002;62(8):1143-72.

17. Platt OS. Hydroxyurea for the treatment of sickle cell anemia. N Engl J Med 2008 Mar 27;358(13):1362-9.

18. Platt OS, Orkin SH, Dover G, Beardsley GP, Miller B, Nathan DG. Hydroxyurea enhances fetal hemoglobin production in sickle cell anemia. J Clin Invest 1984 Aug;74(2):652-6.

19. Steinberg MH, McCarthy WF, Castro O, Ballas SK, Armstrong FD, Smith W, et al. The risks and benefits of long-term use of hydroxyurea in sickle cell anemia: A 17.5 year follow-up. Am J Hematol 2010 Jun;85(6):403-8.

20. Ballas SK, Bauserman RL, McCarthy WF, Castro OL, Smith WR, Waclawiw MA. Hydroxyurea and acute painful crises in sickle cell anemia: effects on hospital length of stay and opioid utilization during hospitalization, outpatient acute care contacts, and at home. J Pain Symptom Manage 2010 Dec;40(6):870-82.

21. Davies S, Olujohungbe A. Hydroxyurea for sickle cell disease. Cochrane Database Syst Rev 2001(2):CD002202.

22. Ballas SK, Marcolina MJ, Dover GJ, Barton FB. Erythropoietic activity in patients with sickle cell anaemia before and after treatment with hydroxyurea. $\mathrm{Br}$ J Haematol 1999 May;105(2):491-6.

23. Charache S, Terrin ML, Moore RD, Dover GJ, Barton FB, Eckert SV, et al. Effect of hydroxyurea on the frequency of painful crises in sickle cell anemia. Investigators 
of the Multicenter Study of Hydroxyurea in Sickle Cell Anemia. N Engl J Med 1995 May 18;332(20):1317-22.

24. Charache S, Barton FB, Moore RD, Terrin ML, Steinberg MH, Dover GJ, et al. Hydroxyurea and sickle cell anemia. Clinical utility of a myelosuppressive "switching" agent. The Multicenter Study of Hydroxyurea in Sickle Cell Anemia. Medicine 1996 Nov;75(6):300-26.

25. Alvarez O, Miller ST, Wang WC, Luo Z, McCarville MB, Schwartz GJ, et al. Effect of hydroxyurea treatment on renal function parameters: results from the multi-center placebo-controlled BABY HUG clinical trial for infants with sickle cell anemia. Pediatr Blood Cancer 2012 Oct;59(4):668-74.

26. Armstrong FD, Elkin TD, Brown RC, Glass P, Rana S, Casella JF, et al. Developmental function in toddlers with sickle cell anemia. Pediatrics 2013 Feb;131(2):e406-14.

27. Lebensburger JD, Miller ST, Howard TH, Casella JF, Brown RC, Lu M, et al. Influence of severity of anemia on clinical findings in infants with sickle cell anemia: analyses from the BABY HUG study. Pediatr Blood Cancer 2012 Oct;59(4):675-8. 28. McGann PT, Flanagan JM, Howard TA, Dertinger SD, He J, Kulharya AS, et al. Genotoxicity associated with hydroxyurea exposure in infants with sickle cell anemia: results from the BABY-HUG phase III clinical trial. Pediatr Blood Cancer 2012 Aug;59(2):254-7.

29. Wang WC, Ware RE, Miller ST, Iyer RV, Casella JF, Minniti CP, et al. Hydroxycarbamide in very young children with sickle-cell anaemia: a multicentre, randomised, controlled trial (BABY HUG). Lancet 2011 May 14;377(9778):1663-72. 30. Ware RE, Rees RC, Sarnaik SA, Iyer RV, Alvarez OA, Casella JF, et al. Renal function in infants with sickle cell anemia: baseline data from the BABY HUG trial. J Pediatr 2010 Jan;156(1):66-70.

31. Kauf TL, Coates TD, Huazhi L, Mody-Patel N, Hartzema AG. The cost of health care for children and adults with sickle cell disease. Am J Hematol 2009 Jun;84(6):323-7.

32. Lanzkron S, Haywood C, Segal JB, Dover GJ. Hospitalization rates and costs of care of patients with sickle-cell anemia in the state of Maryland in the era of hydroxyurea. Am J Hematol 2006 Dec;81(12):927-32.

33. Moore RD, Charache S, Terrin ML, Barton FB, Ballas SK. Cost-effectiveness of hydroxyurea in sickle cell anemia. Investigators of the Multicenter Study of Hydroxyurea in Sickle Cell Anemia. Am J Hematol 2000 May;64(1):26-31.

34. Benjamin LJ, Swinson GI, Nagel RL. Sickle cell anemia day hospital: an approach for the management of uncomplicated painful crises. Blood 2000 Feb 15;95(4):1130-6.

35. Ballas SK. The cost of health care for patients with sickle cell disease. Am J Hematol 2009 Jun;84(6):320-2.

36. Manwani D, Frenette PS. Vaso-occlusion in sickle cell disease: pathophysiology and novel targeted therapies. Hematology Am Soc Hematol Educ Program 2013;2013:362-9.

-. An excellent overview and most recent discussion of investigational therapies and pathophysiology of Sickle Cell Disease. 
37. Kaul DK, Finnegan E, Barabino GA. Sickle red cell-endothelium interactions. Microcirculation 2009 Jan;16(1):97-111.

38. Madigan C, Malik P. Pathophysiology and therapy for haemoglobinopathies. Part I: sickle cell disease. Expert Rev Mol Med 2006;8(9):1-23.

39. Gutsaeva DR, Parkerson JB, Yerigenahally SD, Kurz JC, Schaub RG, Ikuta T, et al. Inhibition of cell adhesion by anti-P-selectin aptamer: a new potential therapeutic agent for sickle cell disease. Blood 2011 Jan 13;117(2):727-35.

40. Turhan A, Weiss LA, Mohandas N, Coller BS, Frenette PS. Primary role for adherent leukocytes in sickle cell vascular occlusion: a new paradigm. Proc Natl Acad Sci U S A 2002 Mar 5;99(5):3047-51.

41. Zennadi R, Moeller BJ, Whalen EJ, Batchvarova M, Xu K, Shan S, et al. Epinephrine-induced activation of LW-mediated sickle cell adhesion and vasoocclusion in vivo. Blood 2007 Oct 1;110(7):2708-17.

42. Hines PC, Zen Q, Burney SN, Shea DA, Ataga KI, Orringer EP, et al. Novel epinephrine and cyclic AMP-mediated activation of BCAM/Lu-dependent sickle (SS) RBC adhesion. Blood 2003 Apr 15;101(8):3281-7.

43. Schaer DJ, Buehler PW, Alayash AI, Belcher JD, Vercellotti GM. Hemolysis and free hemoglobin revisited: exploring hemoglobin and hemin scavengers as a novel class of therapeutic proteins. Blood 2013 Feb 21;121(8):1276-84.

44. Morris CR, Kato GJ, Poljakovic M, Wang X, Blackwelder WC, Sachdev V, et al. Dysregulated arginine metabolism, hemolysis-associated pulmonary hypertension, and mortality in sickle cell disease. JAMA 2005 Jul 6;294(1):81-90.

45. Kato GJ, Wang Z, Machado RF, Blackwelder WC, Taylor JGt, Hazen SL. Endogenous nitric oxide synthase inhibitors in sickle cell disease: abnormal levels and correlations with pulmonary hypertension, desaturation, haemolysis, organ dysfunction and death. Br J Haematol 2009 May;145(4):506-13.

46. Chantrathammachart P, Pawlinski R. Tissue factor and thrombin in sickle cell anemia. Thromb Res 2012 May;129 Suppl 2:S70-2.

47. Chirico EN, Pialoux V. Role of oxidative stress in the pathogenesis of sickle cell disease. IUBMB Life 2012 Jan;64(1):72-80.

48. Gizi A, Papassotiriou I, Apostolakou F, Lazaropoulou C, Papastamataki M, Kanavaki I, et al. Assessment of oxidative stress in patients with sickle cell disease: The glutathione system and the oxidant-antioxidant status. Blood Cells Mol Dis 2011 Mar 15;46(3):220-5.

49. Nur E, Biemond BJ, Otten HM, Brandjes DP, Schnog JJ. Oxidative stress in sickle cell disease; pathophysiology and potential implications for disease management. Am J Hematol 2011 Jun;86(6):484-9.

50. Meiler SE, Wade M, Kutlar F, Yerigenahally SD, Xue Y, Moutouh-de Parseval LA, et al. Pomalidomide augments fetal hemoglobin production without the myelosuppressive effects of hydroxyurea in transgenic sickle cell mice. Blood 2011 Jul 28;118(4):1109-12.

51. Kutlar A, Ataga K, Reid M, Vichinsky EP, Neumayr L, Blair-Britt L, et al. A phase 1/2 trial of HQK-1001, an oral fetal globin inducer, in sickle cell disease. Am J Hematol 2012 Nov;87(11):1017-21. 
52. Elias DB, Barbosa MC, Rocha LB, Dutra LL, Silva HF, Martins AM, et al. Larginine as an adjuvant drug in the treatment of sickle cell anaemia. Br J Haematol 2013 Feb;160(3):410-2.

53. Saunthararajah Y, Hillery CA, Lavelle D, Molokie R, Dorn L, Bressler L, et al. Effects of 5-aza-2'-deoxycytidine on fetal hemoglobin levels, red cell adhesion, and hematopoietic differentiation in patients with sickle cell disease. Blood 2003 Dec 1;102(12):3865-70.

54. Lavelle D, Vaitkus K, Ling Y, Ruiz MA, Mahfouz R, Ng KP, et al. Effects of tetrahydrouridine on pharmacokinetics and pharmacodynamics of oral decitabine. Blood 2012 Feb 2;119(5):1240-7.

55. Hebbel RP, Vercellotti GM, Pace BS, Solovey AN, Kollander R, Abanonu CF, et al. The HDAC inhibitors trichostatin A and suberoylanilide hydroxamic acid exhibit multiple modalities of benefit for the vascular pathobiology of sickle transgenic mice. Blood 2010 Mar 25;115(12):2483-90.

56. GlycoMimetics. GlycoMimetics Announces Presentation of Rivipansel Data in Pediatric Patients at American Society of Pediatric Hematology Oncology 27th Annual Meeting. 2014 May 15.

57. Chang J, Patton JT, Sarkar A, Ernst B, Magnani JL, Frenette PS. GMI-1070, a novel pan-selectin antagonist, reverses acute vascular occlusions in sickle cell mice. Blood 2010 Sep 9;116(10):1779-86.

58. Chang J, Shi PA, Chiang EY, Frenette PS. Intravenous immunoglobulins reverse acute vaso-occlusive crises in sickle cell mice through rapid inhibition of neutrophil adhesion. Blood 2008 Jan 15;111(2):915-23.

59. Qari MH, Aljaouni SK, Alardawi MS, Fatani H, Alsayes FM, Zografos P, et al. Reduction of painful vaso-occlusive crisis of sickle cell anaemia by tinzaparin in a double-blind randomized trial. Thromb Haemost 2007 Aug;98(2):392-6.

60. Kutlar A, Ataga KI, McMahon L, Howard J, Galacteros F, Hagar W, et al. A potent oral P-selectin blocking agent improves microcirculatory blood flow and a marker of endothelial cell injury in patients with sickle cell disease. Am J Hematol 2012 May;87(5):536-9.

61. De Castro LM, Zennadi R, Jonassaint JC, Batchvarova M, Telen MJ. Effect of propranolol as antiadhesive therapy in sickle cell disease. Clin Transl Sci 2012 Dec;5(6):437-44.

62. Lim MY, Ataga KI, Key NS. Hemostatic abnormalities in sickle cell disease. Curr Opin Hematol 2013 Sep;20(5):472-7.

63. Lee SP, Ataga KI, Zayed M, Manganello JM, Orringer EP, Phillips DR, et al. Phase I study of eptifibatide in patients with sickle cell anaemia. Br J Haematol 2007 Nov;139(4):612-20.

64. Desai PC, Brittain JE, Jones SK, McDonald A, Wilson DR, Dominik R, et al. A pilot study of eptifibatide for treatment of acute pain episodes in sickle cell disease. Thromb Res 2013 Sep;132(3):341-5.

65. Field JJ, Lin G, Okam MM, Majerus E, Keefer J, Onyekwere O, et al. Sickle cell vaso-occlusion causes activation of iNKT cells that is decreased by the adenosine A2A receptor agonist regadenoson. Blood 2013 Apr 25;121(17):3329-34. 
66. Scheuplein F, Thariath A, Macdonald S, Truneh A, Mashal R, Schaub R. A humanized monoclonal antibody specific for invariant Natural Killer T (iNKT) cells for in vivo depletion. PLoS One 2013;8(9):e76692.

67. Beckman JD, Belcher JD, Vineyard JV, Chen C, Nguyen J, Nwaneri MO, et al. Inhaled carbon monoxide reduces leukocytosis in a murine model of sickle cell disease. Am J Physiol Heart Circ Physiol 2009 Oct;297(4):H1243-53.

68. Belcher JD, Young M, Chen C, Nguyen J, Burhop K, Tran P, et al. MP4CO, a pegylated hemoglobin saturated with carbon monoxide, is a modulator of HO-1, inflammation, and vaso-occlusion in transgenic sickle mice. Blood 2013 Oct 10;122(15):2757-64.

69. Hoppe C, Kuypers F, Larkin S, Hagar W, Vichinsky E, Styles L. A pilot study of the short-term use of simvastatin in sickle cell disease: effects on markers of vascular dysfunction. Br J Haematol 2011 Jun;153(5):655-63.

70. Daak AA, Ghebremeskel K, Hassan Z, Attallah B, Azan HH, Elbashir MI, et al. Effect of omega-3 (n-3) fatty acid supplementation in patients with sickle cell anemia: randomized, double-blind, placebo-controlled trial. Am J Clin Nutr 2013 Jan;97(1):37-44.

71. Zafarullah M, Li WQ, Sylvester J, Ahmad M. Molecular mechanisms of Nacetylcysteine actions. Cell Mol Life Sci 2003 Jan;60(1):6-20.

72. Pace BS, Shartava A, Pack-Mabien A, Mulekar M, Ardia A, Goodman SR. Effects of $\mathrm{N}$-acetylcysteine on dense cell formation in sickle cell disease. Am J Hematol 2003 May;73(1):26-32.

73. Jakubowski JA, Zhou C, Small DS, et al. A phase 1 study of prasugrel in subjects with sickle cell disease: effects on in vivo markers of platelet activation and of coagulation. Blood (ASH Annual Meeting Abstracts) 2011;118:1049.

74. Jakubowski JA, Zhou C, Jurcevic S, Winters KJ, Lachno DR, Frelinger AL, 3rd, et al. A phase 1 study of prasugrel in patients with sickle cell disease: effects on biomarkers of platelet activation and coagulation. Thromb Res 2014 Feb;133(2):190-5.

75. Wun T, Soulieres D, Frelinger AL, Krishnamurti L, Novelli EM, Kutlar A, et al. A double-blind, randomized, multicenter phase 2 study of prasugrel versus placebo in adult patients with sickle cell disease. J Hematol Oncol 2013;6:17.

76. Gladwin MT, Kato GJ, Weiner D, Onyekwere OC, Dampier C, Hsu L, et al. Nitric oxide for inhalation in the acute treatment of sickle cell pain crisis: a randomized controlled trial. JAMA 2011 Mar 2;305(9):893-902.

77. Morris CR, Morris SM, Jr., Hagar W, Van Warmerdam J, Claster S, KepkaLenhart D, et al. Arginine therapy: a new treatment for pulmonary hypertension in sickle cell disease? Am J Respir Crit Care Med 2003 Jul 1;168(1):63-9.

78. Morris CR, Ansari M, Lavrisha L, et al. Arginine therapy for vaso-occlusive pain episodes in sickle cell disease. Blood (ASH Annual Meeting Abstracts) 2009;114:573.

79. Morris CR, Kuypers FA, Lavrisha L, Ansari M, Sweeters N, Stewart M, et al. A randomized, placebo-controlled trial of arginine therapy for the treatment of children with sickle cell disease hospitalized with vaso-occlusive pain episodes. Haematologica 2013 Sep;98(9):1375-82. 
80. Morris CR, Suh JH, Hagar W, Larkin S, Bland DA, Steinberg MH, et al. Erythrocyte glutamine depletion, altered redox environment, and pulmonary hypertension in sickle cell disease. Blood 2008 Jan 1;111(1):402-10.

81. Niihara Y, Matsui NM, Shen YM, Akiyama DA, Johnson CS, Sunga MA, et al. Lglutamine therapy reduces endothelial adhesion of sickle red blood cells to human umbilical vein endothelial cells. BMC Blood Disord 2005 Jul 25;5:4.

82. Lal A, Atamna W, Killilea DW, Suh JH, Ames BN. Lipoic acid and acetylcarnitine reverse iron-induced oxidative stress in human fibroblasts. Redox Rep 2008;13(1):2-10.

83. Hannemann A, Cytlak UM, Rees DC, Tewari S, Gibson JS. Effects of 5hydroxymethyl-2-furfural on the volume and membrane permeability of red blood cells from patients with sickle cell disease. J Physiol 2014 Jul 11.

84. Singh PC, Ballas SK. Drugs for preventing red blood cell dehydration in people with sickle cell disease. Cochrane Database Syst Rev 2007(4):CD003426. 85. Nagalla S, Ballas SK. Drugs for preventing red blood cell dehydration in people with sickle cell disease. Cochrane Database Syst Rev 2012;7:CD003426. 
Table 1. Emerging Drug Therapies for the Treatment of Sickle Cell Disease

\begin{tabular}{|c|c|c|c|}
\hline KEYWORDS & SYNONYMS & ABBREV. & CONTEXT \\
\hline Decitabine & 5-aza-2'-deoxycytidine & $\begin{array}{l}\text { 5-aza-dCyd; DAC; Dacogen; } \\
\text { Dacogen (IV); Dacogen (SC); } \\
\text { deoxyazacytidine; dezocitidine; } \\
\text { E7373; E7373 (IV); E7373 (oral); } \\
\text { E7373 (SC); JNJ-30979754 (IV); } \\
\text { NSC-127716 }\end{array}$ & Hemoglobin F induction \\
\hline Sodium butyrate & Butyric acid sodium salt & SB & Hemoglobin $\mathrm{F}$ induction \\
\hline Vorintostat & Suberanilohydroxamic acid & $\begin{array}{l}\text { rINN; L-001079038; MK-0683; } \\
\text { MSK-390; SAHA (IV); } \\
\text { suberoylanilide hydroxamic acid; } \\
\text { VOR; vorinostat; Zolinza }\end{array}$ & Hemoglobin $\mathrm{F}$ induction \\
\hline Panobinostat & $\begin{array}{l}\text { (2E)-N-Hydroxy-3-[4-[[[2-(2-methyl-1H-indol-3- } \\
\text { yl)ethyl]amino]methyl]phenyl]-2-propenamide }\end{array}$ & $\begin{array}{l}\text { Faridak; LBH-589; } \\
\text { panobinostat lactate; }\end{array}$ & Hemoglobin $\mathrm{F}$ induction \\
\hline Rivipansel Sodium & GMI-1070 & $\begin{array}{l}\text { GMI-1010; GMI-1011; GMI-1043; } \\
\text { GMI-1070; PF-06460031; } \\
\text { PF06460031; selectin inhibitors, } \\
\text { GlycoMimetics }\end{array}$ & Inhibits cellular adhesion \\
\hline Intravenous immunoglobulin & Intravenous immunoglobulin & IVIG & Inhibits cellular adhesion \\
\hline Low molecular weight heparin & Low molecular weight heparin & LMWH & Inhibits cellular adhesion \\
\hline Dalteparin & Dalteparin sodium & Fragim & Inhibits cellular adhesion \\
\hline SelG1 & PselhmAb & PselhmAb; SelG1 & Inhibits cellular adhesion \\
\hline Propranolol & 1-(isopropylamino)-3-(1-naphthyloxy)propan-2-ol & INN; Verex; Problok; Yissum & Inhibits cellular adhesion \\
\hline $\begin{array}{l}\text { Adenosine } 2 \mathrm{~A} \text { receptor } \\
\text { antagonist }\end{array}$ & ADORA2A & CVT-3146 & Anti-inflammatory agent \\
\hline $\mathrm{ADP}$ receptor antagonist & Ticlopidine, Tagren; ticlopidine; anagregal; & $\begin{array}{l}\text { KRKA; DE-4160; CS-747; LY- } \\
\text { 640315; HL-006 }\end{array}$ & Anti-inflammatory agent \\
\hline Omega-3-acid ethyl esters & Omega-3-acid ethyl esters & Lovaza & Anti-inflammatory agent \\
\hline $\mathrm{N}$-acetyl cysteine & Acetyl Cysteine & EN-3285; RK-0202 & Anti-inflammatory agent \\
\hline Alpha lipoic acid & Acetate Replacing Factor & Thioctic acid, Meda & Anti-inflammatory agent \\
\hline $\begin{array}{l}\text { Nonionic polyoxyethylene- } \\
\text { polyoxypropylene }\end{array}$ & Poloxamer 188 & $\begin{array}{l}\text { ANX-188; CRL-5861; Flocor; MST- } \\
\text { 188; MST188; P-188; P188; } \\
\text { poloxamer 188, purified-1, CytRx; } \\
\text { purified poloxamer 188, CytRx; } \\
\text { vepoloxamer }\end{array}$ & Surfactant \\
\hline Purified Poloxamer 188 & MST-188 & CytRX; RheothRx & Reduces viscosity \\
\hline Niacin & Pyridine-3-carboxylic acid & Vitamin $\mathrm{B}_{3}$ & Increases levels of HDL \\
\hline Rivaroxaban & BAY 59-7939 & JNJ-39039039; Xarelto & Antiplatelet agent \\
\hline Abciximab & c7E3 Fab & $\begin{array}{l}\text { 7E3; anti-GPIIb/IIIa MAb; CentoRx; } \\
\text { ReoPro }\end{array}$ & Platelet aggregation inhibitor \\
\hline Eptifibatide & Integrilin & Velofibatide & Antiplatelet agent \\
\hline Acetylsalicylic acid & Aspirin; Benzon; Acetard; Eurand; Levius & BAN; ASA & Antiplatelet agent \\
\hline Dipyridamole & Dipyridamine & Elan & Red blood cell hydration \\
\hline Magnesium & $\begin{array}{l}\text { Magnesium citrate, magnesium sulfate, magnesium } \\
\text { carbonate }\end{array}$ & $\mathrm{Mg}$ & Red blood cell hydration \\
\hline Nitric oxide & Nitrogen oxide & $\mathrm{NO}$ & Vasodilator \\
\hline Sodium Nitrate & Caliche & $\mathrm{NaNO}_{3}$ & Vasodilator \\
\hline Cholecalciferol & 25-hydroxyvitamin $\mathrm{D}_{3}$ & Vitamin $\mathrm{D}_{3}$ & Supplementary vitamin \\
\hline Saproterin dihydrochloride & $\begin{array}{l}\text { (6R)-2-Amino-6-[(1R,2S)-1,2-dihydroxypropyl]- } \\
\text { 5,6,7,8-tetrahydro-4(1H)-pteridinone dihydrochloride }\end{array}$ & Kuvan & Phenylalanine Hydroxylase activator \\
\hline Senicapoc & ICA 17043 & $\begin{array}{l}\text { ICA-17043; KCa3.1 programme, } \\
\text { Icagen; senicapoc }\end{array}$ & Gardos channel inhibitor \\
\hline Arginine & 2-Amino-5-guanidinopentanoic acid & Arg & Vasodilator \\
\hline HQK 1001 & 2,2-Dimethylbutyrate & Sodium ST20 & Gamma globin gene promoter \\
\hline MP4CO & $\begin{array}{l}\text { Pegylated hemoglobin saturated with carbon } \\
\text { monoxide }\end{array}$ & $\begin{array}{l}\text { Haemoglobin, Sangart-3; MP-4, } \\
\text { Sangart; MP4; MP4-CO; MP4CO; } \\
\text { PEG carboxyhemoglobin, Sangart; } \\
\text { Pegylated carboxyhemoglobin, } \\
\text { Sangart }\end{array}$ & Prevents microvascular stasis \\
\hline L-citrulline & 2-amino-5-(carbamoylamino)pentanoic acid & Asklepion; citrupress & Vasodilator \\
\hline NKTT120 & NKTT-120 & NKTT-120 & $\begin{array}{l}\text { Reduce chronic inflammation associated with } \\
\text { sickle cell disease }\end{array}$ \\
\hline AES-103 & 5-hydroxymethyl-2-furfural & 5-HMF; Xechem & Anti-sickling agent \\
\hline Varespladib sodium & $\mathrm{A}-001$ & A-001; LY-315920; LY-315920Na; & Inhibitor of secretory phospholipases A2 (sPLA2) \\
\hline
\end{tabular}




\begin{tabular}{|l|l|l|l|}
\hline & & $\begin{array}{l}\text { LY315920-Na; LY315920/S-5920; } \\
\text { S-5920; varepladib sodium; }\end{array}$ & \\
\hline TRF-1101 & Pentosan polysulfate sodium & TRF-1101 & Anti-sickling agent \\
\hline Glutamine & Glutamine & Gin, Q & Anti-sickling agent \\
\hline PF 04447943 & $\begin{array}{l}\text { 6-[(3S,4S)-4-methyl-1-(pyrimidin-2- } \\
\text { ylmethyl)pyrrolidin-3-yl]-1-(tetrahydro-2H-pyran-4- } \\
\text { yl)-1,5-dihydro-4H-pyrazolo[3,4-d]pyrimidin-4-one }\end{array}$ & $\begin{array}{l}\text { PDE-IX; PDE9i; phosphodiesterase } \\
\text { 9A inhibitor; PF-4447943 }\end{array}$ & Selective PDE 9 inhibitor \\
\hline
\end{tabular}

